\title{
Is birth weight determined genetically?
}

\author{
ROY CARR-HILL， DORIS M CAMPBELL， MARION H HALL， ANNE MEREDITH
}

\begin{abstract}
Birthweight correlations were analysed among 505 intergenerational pairs of first births to women aged 18-25 identified from a large obstetric data bank. After standardisation for fetal sex, maternal height, gestational age, and proteinuric pre-eclampsia residual correlations of between 0.1402 and 0.1725 were found, suggesting only a small genetic effect.

It is concluded that genetic factors play only a small part in determining birth weight.
\end{abstract}

\section{Introduction}

The extent to which birth weight is determined genetically has clear implications for understanding the physiology of pregnancy and for the delivery of health care but has rarely been examined. Early emphasis on the importance of genetic factors was measured by the similarity of birth weights among relatives. ${ }^{1-3}$ The size of the effects noted was substantial with a correlation of between 0.4273 and 0.502 for sibs $^{2}$ and between 0.135 and 0.24 for maternal first cousins. A study of the offspring of monozygotic and dizygotic twins suggested a major genetic effect. ${ }^{4}$ Zygosity in studies published so far, however, has been presumed from the sex of the twins and not accurately determined, and other confounding factors have not been taken into account. Other workers have suggested a substantial familial effect in the correlation between pregnancy outcomes in successive pregnancies. ${ }^{56}$

None of these studies, however, has disentangled true genetic factors (operating via genes) from other (possibly environmental) factors associated with family membership. An appropriate test

Institute of Medical Sociology, Aberdeen University ROY CARR-HILL, BA, DPHIL, research statistician

Department of Obstetrics and Gynaecology, Aberdeen University DORIS M CAMPBELL, MD, MRCOG, senior lecturer MARION H HALL, MD, FRCOG, consultant obstetrician and gynaecologist ANNE MEREDITH, MBCS, research fellow

Correspondence to: Dr Marion H Hall, Department of Obstetrics and Gynaecology, University of Aberdeen, Foresterhill, Aberdeen AB9 2ZD. of the possibility of a genetic effect on birth weight between generations requires study of both generations and, as far as possible, controlling for confounding factors. The paucity of studies is mainly because of the lack of appropriate data, given the logistical difficulty of investigating similarities between reproductive performance over generations. The few studies that exist depended on grandmothers recollecting the birth weights of their offspring; there were no data on gestation at delivery, and the studies tended to use grouped birth weights rather than the whole range. ${ }^{7-9}$

By utilising the long established Aberdeen Maternity and Neonatal Data Bank ${ }^{10}$ we have compared measured birth weights of a closely defined population of grandmother-mother pairs, all giving birth in one city. Information is available on important factors which have previously been shown to affect birth weight, such as gestational age, fetal sex, maternal height, ${ }^{11}$ parity, ${ }^{12}$ maternal age,,${ }^{13}$ and proteinuric pre-eclampsia. ${ }^{14} \mathrm{By}$ allowing for these factors any remaining environmental covariation between generations should be small.

\section{Subjects and methods}

The Aberdeen Maternity and Neonatal Data Bank comprises 130000 separate pregnancy events (births and spontaneous and induced abortions) in women resident in Aberdeen City District (previously Aberdeen City and suburbs) since 1950 . The first task was to identify possible intergenerational pairs. The search for first generation mothers (referred to in this series as grandmothers) who gave birth to a liveborn singleton daughter in their first pregnancy was restricted to 1950-6. Relevant records for their daughtersthe second generation "mothers" whose first birth was a liveborn singletonwere extracted from 1968 to 1981 .

The analysis was restricted to primigravidas giving birth between the ages of 18 and 25 in both generations. . ultigravidas were not considered because of the extra complexity of standar ing for parity, but also because the birth weight in second and subsequent 1 nancies is associated more closely with the birth weight of the previous ${ }^{1}$-y than with maternal characteristics. ${ }^{5}$ The restriction on age was partly because birth weight is lower in young teenagers, of whom there were more in the second generation studied, but mainly because daughters of the older, first generation would not have had time to reproduce at the same ages as their mothers.

Once these two groups of possible grandmother-mother records had been selected linkage between them was established by using the date of event for the "grandmothers" and the date of birth of the "mother." Potential matches were then verified by using the grandmother's surname and mother's maiden name. Matching was carried out by using the software tools available within the scientific information retrieval database management system. 
The appropriate records for grandmother-mother pairs were then extracted on to a subset database which consisted of only those 505 cases for subsequent analysis, by the statistical package for the social sciences $\mathrm{X}$, to compare and correlate the grandmothers' characteristics with those of the mothers.

Determination of a genetic effect is plainly difficult as all the factors are in principle correlated-for example, tall women have tall daughters who have big babies. Because of this, and the possible importance of outliers, three sets of results are presented. The first set concerns the distribution of the basic data in each generation and the correlations between these raw values for each generation. In the second set birth weight is adjusted for factors known to influence birth weight which may mask any intergenerational effect. Fetal sex was taken into account by considering mother-daughter and mother-son pairs together and separately; standardisation for maternal height, gestation at delivery, and proteinuric pre-eclampsia was achieved by regressing birth weight for gandmothers and mothers separately on these factors. The third set deals with the proportion of low birthweight $(<2500 \mathrm{~g})$ babies born to mothers who were themselves of low birth weight.

\section{Results}

\section{CHANGES AND CORRELATIONS BETWEEN GENERATIONS}

The ranges of maternal variables were as follows: height varied between 143 and $172 \mathrm{~cm}$ in grandmothers and 147 and $180 \mathrm{~cm}$ in mothers; gestation at delivery varied between 33 and 43 weeks in grandmothers and 25 and 44 weeks in mothers; birth weight varied between 1134 and $4359 \mathrm{~g}$ for grandmothers and 640 and $4720 \mathrm{~g}$ for mothers.

Table I shows the changes between the generations in the study population and their intercorrelations. The two sets of figures were compared by Student's $t$ test for differences between means. Average height increased by $1.4 \mathrm{~cm}$ between grandmothers and mothers $(t=3.58 ; \mathrm{p}<0.001)$ and there was a correlation of 0.48 between the pairs. Mean gestational age at delivery marginally declined, especially in mother-son pairs. The decline in mean gestational age was significant for mother-son pairs $(t=2.99 ; \mathrm{p}<0.01)$ but not for mother-daughter pairs. There was no significant correlation of gestational age between generations for any of the pairs.

Birth weight significantly increased between generations, but only in mother-son pairs $(t=2 \cdot 16 ; \mathrm{p}<0.05)$. There was a significant correlation of around 0.2 between intergenerational pairs. The figure shows the crude birth weights for all grandmother-mother pairs.

The standard deviations of the three variables increased significantly (for all pairs) across generations, tested by an $\mathrm{F}$ test on the ratio of variances.

\section{STANDARDISED BIRTH WEIGHT}

Multiple regression equations calculated to allow for the effect of maternal height, gestation at delivery, and proteinuric pre-eclampsia accounted for around a quarter of the variance in birth weight. The intergenerational effect was represented by the correlations between the residuals of birth weight;

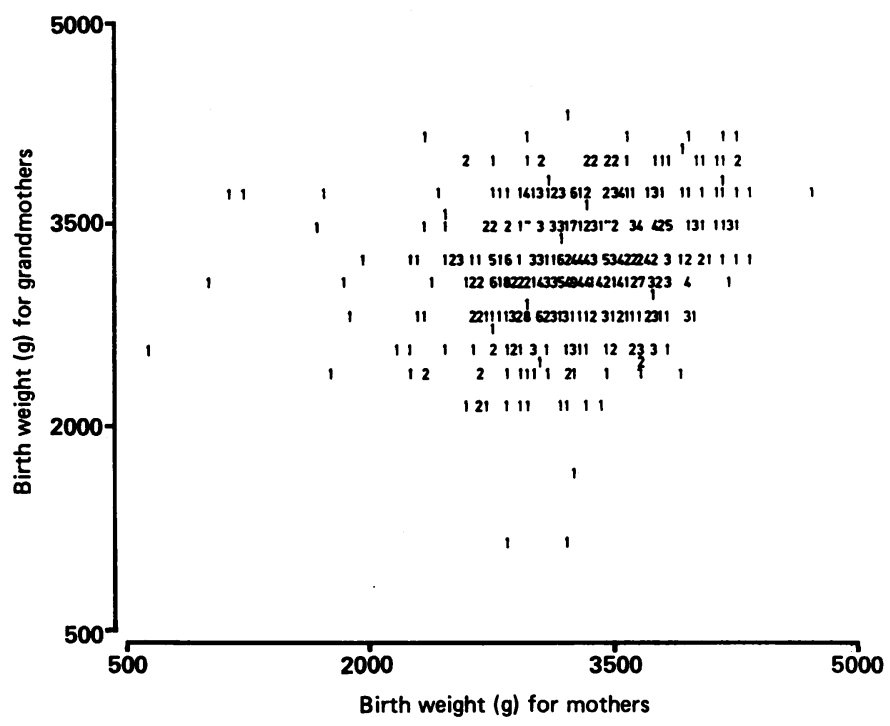

Scatter diagram of crude birth weights for, all grandmother-mother pairs $(n=505)$.

these are shown in table II, separately allowing for height and length of gestation and for height, length of gestation, and proteinuric pre-eclampsia. Correlations were lower than the crude correlations between the raw data, and mother-daughter correlations were higher than mother-son correlations. Including proteinuric pre-eclampsia along with height and gestation at delivery made very little difference to the correlation of the residuals.

\section{LOW BIRTH WEIGHT}

Table III shows the likelihood of low birth weight recurring across generations. The probability of a second generation baby being of low birth weight was raised from $5 \cdot 5 \%$ to $12 \cdot 1 \%$ if the mother was of low birth weight.

\section{Discussion}

These findings are rather different from the secular changes in the whole population of pregnant women in Aberdeen reported elsewhere. ${ }^{15}$ In the whole population average birth weight declined. The probable explanation of the overall secular decline is that over the study period the practice in respect of registering early

TABLE I-Changes and correlations between generations in maternal height, gestation at delivery, and birth weight

\begin{tabular}{|c|c|c|c|c|}
\hline Pair type & Characteristics & $\begin{array}{l}\text { First generation } \\
(\text { mean }(\mathrm{SD}))\end{array}$ & $\begin{array}{l}\text { Pearson correlation } \\
\text { (confidence interval) }\end{array}$ & $\begin{array}{l}\text { Second generation } \\
\quad(\text { mean }(\mathrm{SD}))\end{array}$ \\
\hline All pairs $(n=505)$ & $\left\{\begin{array}{l}\text { Maternal height (cm) } \\
\text { Gestation (weeks) } \\
\text { Birth weight (g) }\end{array}\right.$ & $\begin{array}{c}157 \cdot 4(5 \cdot 5) \\
40 \cdot 5(1 \cdot 7) \\
3206 \cdot 0(460 \cdot 2)\end{array}$ & $\begin{array}{l}0.480(0.409 \text { to } 0.544) \\
0.059(-0.028 \text { to } 0.145) \\
0.215(0.129 \text { to } 0.296)\end{array}$ & $\begin{array}{c}158 \cdot 8(6 \cdot 2) \\
40 \cdot 1(2 \cdot 1) \\
3249 \cdot 5(514 \cdot 6)\end{array}$ \\
\hline Mother-daughter pairs $(n=266)$ & $\left\{\begin{array}{l}\text { Gestation (weeks) } \\
\text { Birth weight (g) }\end{array}\right.$ & $\begin{array}{c}40 \cdot 3(1 \cdot 8) \\
3192 \cdot 5(459 \cdot 0)\end{array}$ & $\begin{array}{l}0.054(-0.067 \text { to } 0.173) \\
0.219(0.102 \text { to } 0.330)\end{array}$ & $\begin{array}{c}40 \cdot 1(2 \cdot 1) \\
3186 \cdot 1(486 \cdot 5)\end{array}$ \\
\hline Mother-son pairs $(n=239)$ & $\left\{\begin{array}{l}\text { Gestation (weeks) } \\
\text { Birth weight (g) }\end{array}\right.$ & $\begin{array}{c}40 \cdot 6(1 \cdot 5) \\
3221 \cdot 1(462 \cdot 1)\end{array}$ & $\begin{array}{l}0.073(-0.054 \text { to } 0.198) \\
0.207(0.082 \text { to } 0.326)\end{array}$ & $\begin{array}{c}40 \cdot 0(2 \cdot 1) \\
3320 \cdot 0(534 \cdot 3)\end{array}$ \\
\hline
\end{tabular}

TABLE II-Correlation of residual birth weight between generations after allowing for maternal height, gestation at delivery, and proteinuric pre-eclampsia

\begin{tabular}{lccc}
\hline & & Correlation of residuals \\
\cline { 2 - 4 } \multicolumn{1}{c}{ Pair type } & $\begin{array}{c}\text { Standardised for maternal height } \\
\text { and gestation at delivery }\end{array}$ & $\begin{array}{c}\text { 95\% Confidence interval } \\
\text { Standardised for maternal height, gestation at delivery, } \\
\text { and proteinuric pre-eclampsia }\end{array}$ & $\begin{array}{c}\text { 95\% Confidence interval } \\
\text { Mother-daughter pairs }(n=266)\end{array}$ \\
Mother-son pairs (n=239) & 0.154 & 0.067 to 0.237 & $0 \cdot 154$ \\
& 0.178 & 0.058 to 0.291 & $0 \cdot 173$ \\
0.001 to 0.260 & 0.067 to 0.237 & 0.053 to 0.287 \\
0.013 to 0.262 & 0.140 \\
\hline
\end{tabular}


gestation, low birthweight infants changed so that more of them are now included: but such births predominate among young teenagers and other mothers, who were not included in this intergenerational study.

Our findings relate to a "pure" set of grandmother-mother pairs restricted to first pregnancies in which the granddaughter survived at least a week. The cross tabulations and statistical correlations

TABLE III-Low birth weight acroṣs generations

\begin{tabular}{lccc}
\hline $\begin{array}{l}\text { Birth weight }(\mathrm{g}) \\
\text { for } \\
\text { grandmothers }\end{array}$ & \multicolumn{3}{c}{ Birth weight (g) for mothers } \\
\cline { 2 - 4 } & $<2500$ & $\geqslant 2500$ & Total \\
\hline$<2500$ & 4 & 29 & 33 \\
$\geqslant 2500$ & 24 & 448 & 472 \\
\hline Total & 28 & 477 & \\
\hline
\end{tabular}

suggest a small relation between the birth weight of the first born offspring of grandmother-mother pairs. But the correlations between the raw variables, which included both genetic and environmental covariation, were small; they were even smaller when birth weights were adjusted for fetal sex, gestation at delivery, and maternal height. Though the likelihood of having a low birthweight baby was raised $2 \cdot 4$-fold when the mother herself was of low birth weight, only four out of $28(14.3 \%)$ low birthweight babies had a low birthweight mother. Whichever results are considered, the effect is not as large as suggested in previous studies. ${ }^{1-357-9}$ In part the difference is due to the failure to disentangle true genetic variation and environmental covariates when studying reproductive performance of relatives, and in part it is due to other confounding factors which can be controlled properly only in a longitudinal study. Also, selection biases from differential recall are inevitable in studies relying on memory. One of the advantages of a data bank is precise recording of birth weight itself and of the relevant associated variables.

Assessment of the balance between genetic and environmental influences has many implications. The data bank is invaluable, and the conclusion from this analysis is that genetic factors play only a small part in determining birth weight.

AM was funded by the Biomedical Research Committee of the Chief Scientist Organisation of the Scottish Home and Health Department. We acknowledge the contribution of B Thompson, G Muhleman, and M L Samphier, of the MRC Medical Sociology Unit, and J Lemon, Aberdeen University Computing Centre, in the study design and data preparation and extractions.

\section{References}

1 Fisher RA. The correlation between relations on the supposition of mendelian inheritance. Transactions of the Royal Sociery of Edinburgh 1918;52:399-404.

2 Robson EB. Birthweight in cousins. Ann Hum Genet 1955;19:262-8.

3 Karn MN, Lang-Brown H, Penrose LS. Birthweight, gestation, time and survival in sibs. Annals of Eugenics 1951;15:306-22.

4 Magnus P. Distinguishing fetal and maternal genetic effects on variation in birthweight. Acta Genet Med Gemellol (Twin Research) 1984;33:481-6.

5 Carr-Hill RA, Samphier ML. Birthweight and reproductive careers. I Biosoc Sci 1983;15:453-64. 6 Carr-Hill RA, Hall MH. Repetition of spontaneous preterm labour. Br J Obstet Gynaecol 1985;92:921-8.

7 Klebanoff MA, Granbard BI, Kessel SS, Berendez HW. Low birthweight across generations. JAMA 1984;252:2423-7.

8 Ounsted M, Ounsted C. Maternal regulation of intrauterine growth. Nature 1966;111:995-7. 9 Ounsted M, Ounsted C. Rate of intrauterine growth. Nature 1968;220:599-600.

10 Samphier ML, Thompeon B. The Aberdeen maternity and neonatal data bank. In: Mednick SA Baert AE, eds. Prospective longinudinal research. Oxford: Oxford University Press, 1981:61-5.

11 Cawey RH, McKeown T, Record RG. Parental stature and birthweight. Am $\mathcal{J}$ Human Genet 1954;6:448-56.

12 McKeown T, Record RG. Influence of prenatal environment on correlation between birthweight and parental height. Am 7 Hum Genet 1954;6:457-63.

13 Institute of Medicine. Preventing low birthweight. Washington, DC: National Academy Press, 1985: appendix table B2.

14 MacGillivray I. The hypertensize disease of pregnancy. London: W B Saunders, 1983:8-26.

15 Carr-Hill RA, Pritchard C. The deoelopment and exploitation of empirical birtheweight standards. London: Macmillan Press, 1985.

(Accepted 21 fuly 1987)
Poetic justice has overtaken the Council of the College of Surgeons of England. It has long ignored the right of its commonalty to have any hand in managing its affairs, and has sought to impose its will without granting to that commonalty more than the semblance of a right to discuss questions even of the most vital importance. It has been supposed to be an oligarchy in which the fortunes of the many were committeed to the irresponsible governance of the few. Recent events have shown that within this oligarchy there is an autocrat. As we announced last week, Mr Savory, who is at present President of the College of Surgeons, received in solitary state an artistocratic deputation, which lodged a protest against the utilisation of the Erasmus Wilson Fund for just the very purpose for which its benevolent founder intended it to be used-the advancement of surgery.

The petition which some well meaning persons, learned, no doubt, in all points concerning their own professions, but obviously quite unacquainted with the requirements and successes of modern medicine and surgery, had been induced to support, contained nothing beyond the usual misstatements, and need not detain us at the present moment. But there is one point of view from which the incident deserves most serious attention. No more lamentable breach of the constitution of the College has ever come to light than the premature-we fear we must also say hospitable-reception of that deputation by $\mathrm{Mr}$ Savory, in his full and official capacity as President of the College. In thus ignoring even the existence of the Council by presuming to receive such a deputation without previous sanction, Mr Savory has acted in a manner which is entirely without precedent, and the circumstances under which he acted aggravate the uffence and intensify the insult. So far as we are aware, no similar act of highhandedness has ever been recorded in the annals of the College. And for what purpose? We hardly like to surmise. It will be noted that Mr Savory arranged to receive the deputation on the day just before that fixed for the meeting of the Council. But why the day before? Simply, we believe, because he was well aware the Council would have nothing to say to the automata forming the embassy of agitation. Was it impossible for Mr Savory to wait two or three days until he could consult the governing body of the College before endeavouring thus to commit the College to his own personal views by his autocratic action? The Council of the College of Surgeons will no doubt in future take steps to frustrate the absurdly self-opiniated attempts of the President to take the reins of government into his own hands, but the whole incident is a striking example of the essentially vicious constitution of the College of Surgeons. If the principle of representation were once frankly admitted, no President would ever dare to act on his own authority in any matter likely to pledge the College to a course of future action. At the present time it would appear that the President is an uncontrolled autocrat.

But, besides thus transgressing every law of constitutionalism and courtesy which surround the honourable office in which he has been placed, Mr Savory has, by sheltering himself behind a technical error, given it to be understood that he will not receive any deputation formed from among those who signed either the circular presented to the Council by all the leading authorities in biological science (including, of course, physiology and pathology), or the circular we published three weeks ago, which was signed by all the teachers of surgery in London (not on the Council), with "two incomprehensible exceptions." That the President of the College of Surgeons of England should by unconstitutional means welcome the enemies of his own professions, and at the same time contemptuously refuse to listen to suggestions offered by the foremost representative men of science, as well as the teachers of surgery, reveals a state of things which is almost incredible in this nineteenth century. An immediate remedy lies in the hands of the Council of the College, and in making it perfectly impossible in the future for anyone, however arrogant and influential, to plan such a stab in the dark as that which Mr Savory has just dealt his own colleagues and profession, the members of that Council will do something towards earning the confidence and esteem of the practitioners they represent as the trustees of English surgery. (British Medical fourmal 1887;i:738.) 